\title{
Myoblast-based cardiac repair: Xenomyoblast versus allomyoblast transplantation
}

\author{
Changfa Guo, MD, a,b Husnain Kh. Haider, PhD, ${ }^{c}$ Winston S. N. Shim, PhD, ${ }^{a, d}$ Ru-San Tan, MBBS, ${ }^{d}$ Lei Ye, MD, PhD, \\ Shujia Jiang, MD, ${ }^{c}$ Peter K. Law, PhD, ${ }^{f}$ Philip Wong, MBBS, ${ }^{d}$ and Eugene K.W. Sim, FRCS ${ }^{a, g}$
}

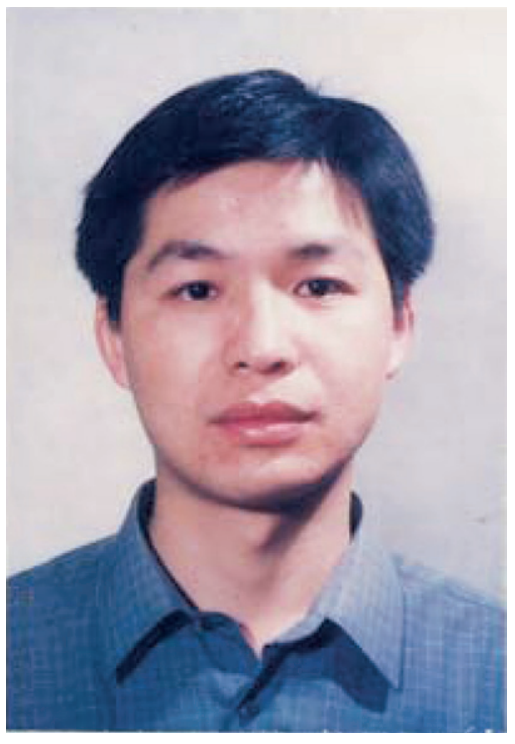

Dr Guo

丹 Supplemental material is available online.

From the Department of Surgery, ${ }^{\text {a National }}$ University of Singapore, Singapore; Department of Cardiac Surgery, ${ }^{\mathrm{b}}$ Zhongshan Hospital, Fudan University, Shanghai, China; Department of Pathology and Laboratory Medicine, ${ }^{\mathrm{c}}$ University of Cincinnati, Cincinnati, Ohio; National Heart Center, ${ }^{\mathrm{d}}$ Singapore; National University Medical Institute, ${ }^{e}$ National University of Singapore, Singapore; Cell Transplants Singapore, Pte Ltd, ${ }^{\mathrm{f}}$ Singapore; and Gleneagles JPMC Cardiac Center, ${ }^{\mathrm{g}}$ Brunei Darussalam.

Supported by a National Medical Research Council grant (Singapore, R176 000077 213).

Received for publication March 9, 2007; revisions received July 9, 2007; accepted for publication July 24, 2007.

Address for reprints: Eugene K. W. Sim, FRCS, B1-12, MD11, National University of Singapore, Singapore 117597 (E-mail: sursimkw@nus.edu.sg).

J Thorac Cardiovasc Surg 2007;134:1332-9

$0022-5223 / \$ 32.00$

Copyright (C) 2007 by The American Association for Thoracic Surgery

doi:10.1016/j.jtcvs.2007.07.025
Objective: We sought to investigate immune cell kinetics in relation to skeletal myoblast survival and heart function improvement after nonautologous skeletal myoblast transplantation in a rat model of myocardial infarction.

Methods: One week after myocardial infarction, 208 Wistar rats were grouped into group $1(\mathrm{n}=24$, receiving $150 \mu \mathrm{L}$ of medium only), group $2(\mathrm{n}=24$, receiving 150 $\mu \mathrm{L}$ of medium and cyclosporine [INN: ciclosporin]), group $3(\mathrm{n}=40$, human skeletal myoblast transplantation), group $4(\mathrm{n}=40$, human skeletal myoblast transplantation with cyclosporine treatment), group $5(\mathrm{n}=40$, rat skeletal myoblast transplantation), and group $6(\mathrm{n}=40$, rat skeletal myoblast transplantation with cyclosporine treatment). The hearts were harvested at 10 minutes and 1, 4, 7, and 28 days after cell transplantation. Skeletal myoblast survival was confirmed by means of immunohistochemical studies and quantified by using real-time polymerase chain reaction. Host immune responses were assessed by immunostaining for macrophages and $\mathrm{CD} 4^{+}$and $\mathrm{CD} 8^{+}$lymphocytes. Heart function was evaluated by means of echocardiographic analysis.

Results: The majority of macrophages and lymphocytes infiltrated in the acute phase (from day 1 to day 7) and then subsided by day 28. The donor skeletal myoblasts survived and differentiated well in all skeletal myoblast transplantation groups. Allogeneic skeletal myoblasts showed a superior survival rate than xenogeneic skeletal myoblasts $(P<.01)$. Cyclosporine inhibited the infiltration of the immunocytes, enhanced skeletal myoblast survival, and improved heart performance compared with that seen in the groups not receiving cyclosporine treatment $(P<.05)$.

Conclusions: Allomyoblasts survive better than do xenomyoblasts after transplantation into infarcted myocardium. After inhibition of immunocyte infiltration by means of immunosuppressive treatment, skeletal myoblast survival is enhanced, with improved heart performance. These findings suggest the feasibility of nonautologous myoblast transplantation with immunosuppressive treatment.

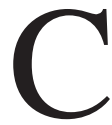
ell-based cardiac repair represents a promising therapeutic approach for heart failure. Among various cell types, skeletal myoblasts (SkMs) have been extensively used for cardiac cell therapy because of their myogenic potential, proliferative capacity, resistance to ischemia, and nontumorigenic nature. Preclinical studies in both small- and large-animal models showed a definite improvement in regional and global left ventricular heart function after SkM engraftment. ${ }^{1-6}$ Most of these studies involved SkMs from either autologous or syngeneic donors. ${ }^{1-4}$ We have previously reported long-term survival of xenomyoblasts using transient immunosuppressive treatment. ${ }^{5,6}$ On the other hand, most clinical studies used autologous SkMs for cardiac repair because their use precluded the concern of immune rejection. ${ }^{7-10}$ However, the use of autologous SkMs is time consuming and less cost-effective and has logistic concerns for large-scale clinical 
applications. The use of SkMs from nonautologous sources might overcome these problems and provide alternate choices for clinicians. The present study provides direct comparison between allomyoblasts and xenomyoblasts after engraftment with respect to their survival, immunologic behavior, and graft efficacy for cardiac repair. In this study we transplanted equal numbers of SkMs purified from male rats and human donors into a female rat model of myocardial infarction to compare their in vivo behavior. This was done to provide us with a better understanding of the early cellular behavior of allomyoblasts and xenomyoblasts and the underlying mechanisms that govern early graft attrition after engraftment into the infarcted heart.

\section{Materials and Methods}

The work was approved by the Institutional Review Board and Institutional Animal Care and Use Committee protocols of the National University of Singapore.

\section{Isolation and Expansion of SkMs}

Human SkMs (hSkMs; kindly provided by Cell Transplants Singapore, Ltd) were isolated from a 20-year-old pathogen-free male donor who provided written consent and were expanded until the required number was achieved. Rat $\mathrm{SkMs}(\mathrm{rSkMs})$ were isolated from male Wistar rats. Isolation of cells was performed as described previously. ${ }^{11}$ Forty-eight hours before muscle harvest, 0.5 $\mathrm{mL}$ of bupivacaine $(0.5 \%$, Astra) was injected into the tibialis anterior muscles of rat hind limbs to achieve a better cell yield. Skeletal muscle (1 g) was harvested, minced, and enzymatically dissociated with collagenase IA ( $2 \mathrm{mg} / \mathrm{mL}$, Sigma) for 1 hour, dispase $(2.4 \mathrm{U} / \mathrm{mL}$, Invitrogen) for 1 hour, and trypsin-ethylenediamine tetraacetic acid $(0.25 \%$, Sigma $)$ for 30 minutes. The muscle cell extract was preplated 3 times at regular time intervals to increase the purity of the purified SkMs. The cells were cultured in patented Super Medium (Cell Transplants Singapore, Ltd) for 4 days after initial seeding and then fed with Dulbecco's modified Eagle's medium (DMEM) supplemented with $20 \%$ fetal bovine serum, $100 \mathrm{U} / \mathrm{mL}$ penicillin, $100 \mu \mathrm{g} / \mathrm{mL}$ streptomycin, and $0.1 \mathrm{mg} / \mathrm{mL}$ L-glutamine until the required number was achieved. The purity of SkMs was assessed by means of immunostaining and flow cytometric analysis for desmin expression with desmin-specific antibody (1:50, Sigma).

\section{Preparation of SkMs Before Transplantation}

For posttransplantation identification, SkMs were double-labeled with the lac-z reporter gene and 4',6'-diamidino-2-phenylindole hydrochloride (DAPI; Sigma).

SkMs were grown to achieve $60 \%$ confluence. The cells were first incubated in $15 \mathrm{~mL}$ of transduction medium containing $1 \times$ $10^{6}$ particles $/ \mathrm{mL}$ retroviral vector carrying the $l a c-z$ reporter gene. Eight hours later, the viral infection medium was replaced with culture medium for 24 hours. The transduction procedure was repeated 3 times. Transduction efficiency was assessed by means of histochemical staining for $l a c-z$ expression.

Before transplantation, SkMs were also incubated in DAPI culture medium $(20 \mu \mathrm{g} / 100 \mathrm{~mL})$ for 24 hours. Incorporation efficiency of DAPI was calculated by dividing the number of blue fluorescent nuclei counted by means of fluorescence microscopic analysis by the total number of cells counted by means of phasecontrast microscopic analysis.

Before cell transplantation, the viability of SkMs was assessed by using the trypan blue (0.4\%, GIBCO) exclusion method.

\section{Histochemistry for lac-z Expression}

The $l a c$ - $z$-transduced SkMs were fixed with $0.5 \%$ glutaraldehyde for 15 minutes at room temperature. After rinsing, the cells were incubated overnight at $37^{\circ} \mathrm{C}$ with $40 \mathrm{mg} / \mathrm{mL}$ 5-bromo-4-chloro3indoyl- $\beta$-D-galactosidase (Bio-Rad) prepared in $1 \times$ PBS buffer containing $30 \mathrm{mmol} / \mathrm{L}$ potassium ferricyanide, $30 \mathrm{mmol} / \mathrm{L}$ potassium ferrocyanide, and $2 \mathrm{mmol} / \mathrm{L}$ magnesium chloride. Next the cells were observed with a light microscope (Olympus Co) for green-stained nuclei. The labeling efficiency was calculated by dividing the number of green-colored nucleus cells counted by means of light microscopic analysis by the total number of cells counted by means of phase-contrast microscopic analysis.

\section{Myocardial Infarction Model and Experimental Groups}

A rat heart model of myocardial infarction was developed in female Wistar rats. The animals were anesthetized with ketamine $(50 \mathrm{mg} / \mathrm{kg}$ administered intraperitoneally) and xylazine $(10 \mathrm{mg} / \mathrm{kg}$ administered intraperitoneally) and mechanically ventilated at a tidal volume of $5 \mathrm{~mL}$ ( $75 \mathrm{cycles} / \mathrm{min})$. The infarction was created by means of permanent ligation of the left anterior descending coronary artery with a 6-0 polypropylene snare.

One week later, 208 animals with myocardial infarction were divided into 6 groups: the DMEM-injected control group $1(\mathrm{n}=$ 24); the DMEM-injected control group 2 with cyclosporine (INN: ciclosporin) treatment $(\mathrm{n}=24)$; the hSkM-transplanted group 3 $(\mathrm{n}=40)$; the hSkM-transplanted group 4 with cyclosporine treatment $(\mathrm{n}=40)$; the rSkM-transplanted group $5(\mathrm{n}=40)$; and the rSkM-transplanted group 6 with cyclosporine treatment $(n=40)$. The hearts were injected with a total of $150 \mu \mathrm{L}$ of DMEM without cells or containing $3 \times 10^{6} \mathrm{hSkMs}$ or rSkMs at 5 different sites in and around the infarcted area.

The animals were killed at 10 minutes and $1,4,7$, and 28 days after cell transplantation. In groups 2, 4, and 6 cyclosporine (10 $\mathrm{mg} \cdot \mathrm{kg}^{-1} \cdot \mathrm{d}^{-1}$ administered intraperitoneally) was administered 5 days before cell transplantation and continuing to animal death. In control groups 1 and 2 there were 4 rats at each time point, except for 8 rats on day 28 . The hearts were frozen in liquid nitrogen-cooled isopentane only for histochemical studies. (No heart was used for polymerase chain reaction [PCR] analysis against a male specific gene, sry, because in our pilot study no signal was detected.) In the other groups there were 8 rats at each time point. Four hearts were used for histochemical study, and the whole left ventricular free wall of the remaining 4 rats was homogenized to extract DNA for PCR analysis.

\section{Quantitative Real-time PCR}

The survival of male donor SkMs was evaluated by using real-time PCR directed at the sry gene with DNA Engine Opticon2 (Bio-Rad). The DNA from homogenized heart tissue was extracted by using the DNeasy kit (QIAGEN), according to the manufacturer's instructions. 
Male genomic DNA from human subjects (Research Instruments) or rats (Biochain) was used as standard after a serial dilution $(5 \times)$. Real-time PCR analysis was performed with the SYBR Green kit (ABgene). Briefly, $5 \mu \mathrm{L}$ of each standard and sample was added to the real-time PCR mixture containing the TaqMan PCR Master Mixture, primers, and fluorescent SYBR Green. The reaction mixture was preheated for 1 minute at $95^{\circ} \mathrm{C}$. The PCR amplification protocol consisted of 45 cycles of denaturation for 15 seconds at $95^{\circ} \mathrm{C}$ and annealing and extending for 1 minute at $60^{\circ} \mathrm{C}$.

The primers were as follows: human sry gene-forward 5'TGGCGATTAAGTCAAATTCGC 3', reverse 5'-CCCCCTAGTACCCGTACAATGTATT-3'; rat sry gene-forward 5' -GCCTCAGGACATATTCTCTGGGAG-3', reverse 5'-GCTGAT CT CTGAATTCTGCATGC- $3^{\prime}$; rat $\beta$-globin gene-forward $5^{\prime}$ AGCCATGAGGGTACCTTCTAGAC-3', reverse 5'-AATTC CTTGCCCAGGTGG-3'.

\section{Histochemical and Immunohistochemical Studies}

Sections of $6 \mu \mathrm{m}$ were cut from frozen slices and observed under a microscope for DAPI florescence (blue). The tissue sections positive for DAPI were processed for further staining. Hematoxylin and eosin staining was performed to observe the tissue architecture. To detect SkM differentiation, immunostaining was performed for skeletal myosin heavy chain fast isoform (1:50, 1 hour, $37^{\circ} \mathrm{C}$; Serotec), skeletal myosin heavy chain slow isoform (1:100, 1 hour, $37^{\circ} \mathrm{C}$; Chemicon), and biotinylated goat antipolyvalent $(8$ minutes, room temperature; Lab Vision) and streptavidin peroxidase ( 8 minutes, room temperature; Lab Vision). The section was then developed with 3,3'-diaminobenzidine tetrahydrochloride substrate for 1 minute.

The immunoreactivity was determined by immunostaining for the infiltration of $\mathrm{CD}^{+}{ }^{+}$and $\mathrm{CD}^{+}$lymphocytes $\left(1: 50,1\right.$ hour, $37^{\circ} \mathrm{C}$; $\mathrm{BD}$ PharMingen) and macrophages (1:20, 1 hour, $37^{\circ} \mathrm{C}$; Serotec) by using their specific antibodies, followed by the rhodamine-conjugated secondary antibody (1:200, 1 hour, room temperature; Chemicon). The numbers of infiltrating macrophages and $\mathrm{CD}^{+}$and $\mathrm{CD} 8^{+}$lymphocytes were counted by using light microscopy. In the process of counting the cell numbers, 5 sections positive for DAPI were chosen in each rat, 3 sections in the middle of the infarction, and 2 sections at remote regions. For each section, 3 fields were chosen at $400 \times$ magnification.

\section{Heart Function Assessment}

Heart function was assessed by means of 2-dimensional echocardiography at 6 days after infarction as baseline determinations and 4 weeks after SkM transplantation to show the efficacy of SkM transplantation. Two-dimensional (and M-mode) measurements were performed with a $10-\mathrm{MHz}$ linear array transducer system (GE). Parasternal long-axis views were obtained to view the regional wall-motion abnormalities. Short-axis M-mode views were obtained perpendicular to the midventricular level, with sweep speeds of $200 \mathrm{~mm} / \mathrm{s}$ confirmed by means of 2-dimensional echocardiography. To obtain a measure of systolic function, dimensional fractional shortening (FS) and ejection fraction (EF) were computed by using the following formulas: $F S=(L V E D-$ $L V E S) / L V E D \times 100 \%$ and $E F=\left(L V E D^{2}-L V E S^{2}\right) / L V E D^{2} \times$ $100 \%$, where LVED is defined as left ventricular end-diastolic dimension and LVES is defined as left ventricular end-systolic dimension.

\section{Statistical Analysis}

The data were analyzed with SPSS 12.0 software (SPSS, Inc). All values were expressed as the mean \pm standard error of the mean. One-way analysis of variance with the post-hoc Tukey test was performed to assess the significant difference among multiple groups. The significant difference between 2 groups was evaluated by using the Student $t$ test.

\section{Results}

The development of myocardial infarction resulted in an $11.9 \%$ (28/236) acute mortality rate within 24 hours. All 208 surviving animals survived the cell transplantation procedure and continued for the full length of the experiment.

\section{Characterization of SkMs}

The purity of hSkMs and rSkMs was $98.89 \%$ and $75.35 \%$, respectively, for desmin expression when gated for control at $1.02 \%$ by means of flow cytometric analysis (Figure E1, $A 1, A 2, B 1$, and B2). The efficiency of DAPI and $l a c-z$ labeling was $100 \%$ and $85 \%$, respectively (Figure E1, C1, $C 2$, and $D$ ). Trypan blue dye exclusion showed greater than $95 \%$ viability of the cell preparations before transplantation.

\section{Cell Survival After Transplantation in Infarcted Rat Hearts}

Extensive survival and differentiation of SkMs was observed in the infarcted rat hearts after engraftment. Until day 7 , the transplanted cells were found clustered at the site of injection without any orientation (Figure E2, A). By day 28, the transplanted SkMs were seen to be aligned and well oriented, which might result from the differentiation of SkMs (Figure E2, B).

On days 1 and 4, we did not detect any skeletal myotube formation. This was shown by the lack of skeletal myosin fast chain and slow chain immunostaining. On day 7, approximately one third of the samples were positive for skeletal myosin fast chain, but none of them were positive for skeletal myosin slow chain. On day 28, almost all samples were positive for skeletal myosin fast chain, and approximately half of the samples were positive for slow chain by means of immunostaining (Figure E2, $D-F$ ). The implanted cells expressed myosin slow chain, which was more adaptable for cardiac pump function. The extensive survival of the engrafted cells was also confirmed by means of lac-z staining (Figure E2, G) and real-time PCR for the sry gene from the male transplanted SkMs in female hearts.

\section{Immune Cell Dynamics After SkM Transplantation} Immunostaining for macrophages and $\mathrm{CD} 4^{+}$and $\mathrm{CD} 8^{+}$ cells and their counts at different time points are shown in Figure 1. 

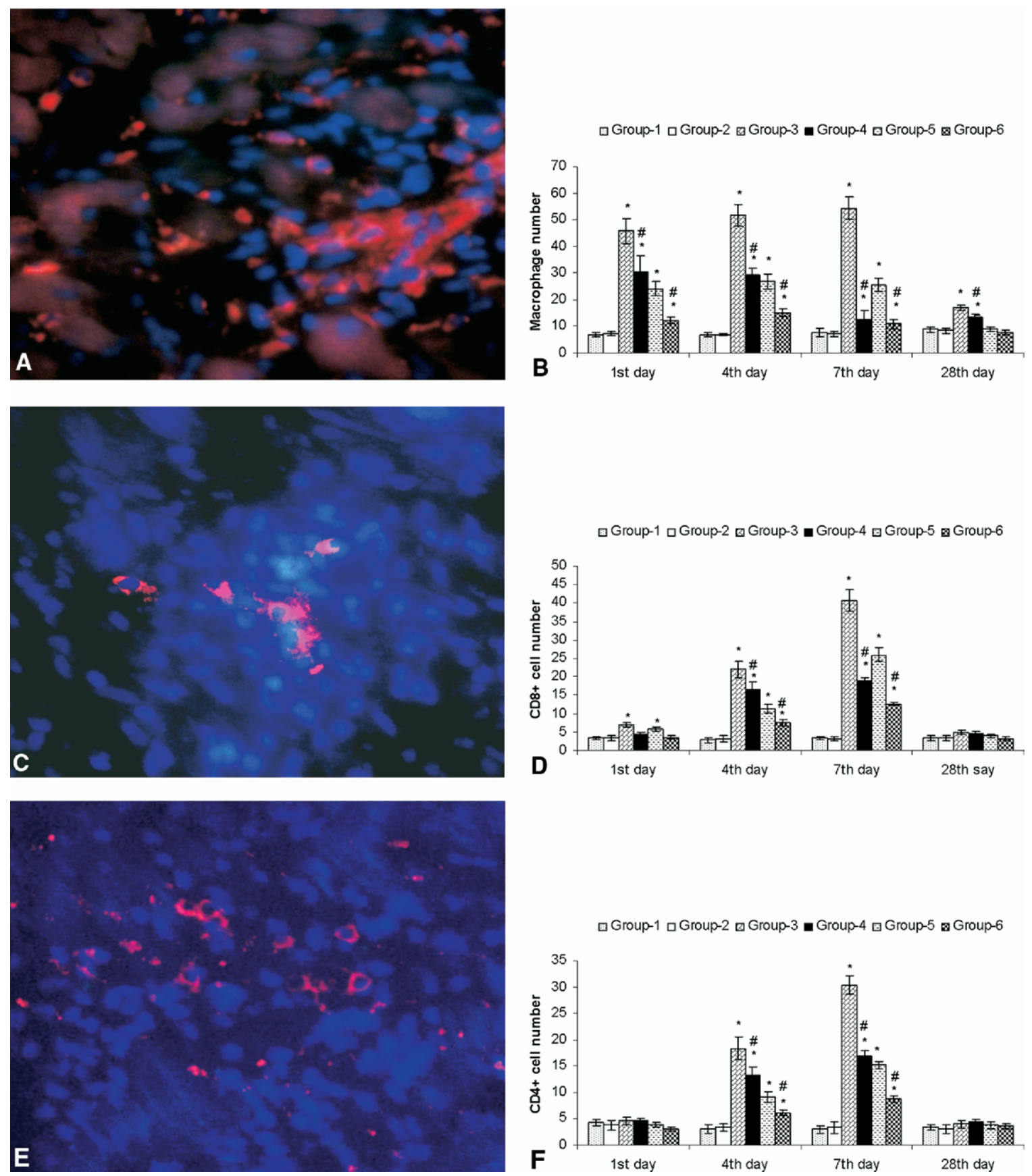

Figure 1. Immunostaining and observation of time of infiltration of macrophages (A and B), CD8 ${ }^{+}$cells (C and D), and $\mathrm{CD}^{+}$cells $(\mathrm{E}$ and $\mathrm{F}$ ) into the cell injection site (magnification $\times 400$ ). *Significantly increased numbers of infiltrating cells (including macrophages, $\mathrm{CD}^{+}$cells, and $\mathrm{CD8}^{+}$cells) compared with those of groups 1 or 2 (groups 3 and 5 vs group 1; groups 4 and 6 vs group $2, P<.01$ ). \#After cyclosporine treatment, the infiltrating cells (including macrophages, $\mathrm{CD}^{+}$cells, and $\mathrm{CD8}^{+}$cells) significantly decreased compared with those in the groups not receiving cyclosporine treatment (group 4 vs group 3 and group 6 vs group $5, P<.01$ ).

Macrophages were the first cells infiltrating into the donor myoblast pockets (Figure 1, $A$ and $B$ ). Immediately after cell transplantation (10 minutes), macrophages were rarely observed at the site of the cell graft. After 24 hours, an intense infiltration by macrophages was apparent in all the transplanted hearts. In group 3 the average number of macrophages was $45.8 \pm 4.55$ (control, $6.8 \pm 0.86$ ). The number of macrophages showed a gradual increase and 
Table 1. The time courses of SkM survival

\begin{tabular}{lcccc}
\hline & $\begin{array}{c}\text { Group 3 } \\
\text { (xeno-SkM graft) }\end{array}$ & $\begin{array}{c}\text { Group 4 } \\
\text { (xeno-SkM + cyclosporine) }\end{array}$ & $\begin{array}{c}\text { Group 5 } \\
\text { (allo-SkM graft) }\end{array}$ & $\begin{array}{c}\text { Group 6 } \\
\text { (allo-SkM + cyclosporine) }\end{array}$ \\
\hline $10 \min$ & $100 \%$ & $100 \%$ & $100 \%$ & $100 \%$ \\
Day 1 & $5.37 \% \pm 0.8 \%$ & $9.26 \% \pm 0.9 \% *$ & $8.83 \% \pm 1.5 \% \dagger$ & $11.10 \% \pm 1.3 \% * \dagger$ \\
Day 4 & $9.01 \% \pm 1.2 \%$ & $15.55 \% \pm 1.6 \% *$ & $12.99 \% \pm 2.1 \% \dagger$ & $26.80 \% \pm 4.3 \% * \dagger$ \\
Day 7 & $17.23 \% \pm 2.8 \%$ & $31.36 \% \pm 2.7 \% *$ & $20.69 \% \pm 3.4 \% \dagger$ & $49.73 \% \pm 5.9 \% * \dagger$ \\
Day 28 & $23.63 \% \pm 1.8 \%$ & $54.68 \% \pm 3.9 \% *$ & $33.55 \% \pm 5.5 \% \dagger$ & $67.87 \% \pm 5.6 \% * \dagger$ \\
\hline
\end{tabular}

The corresponding numbers (means \pm standard error of the mean) are copy numbers of male DNA from the hearts harvested at different time points divided by the copy numbers of male DNA at 10 minutes. ${ }^{*}$ Significant difference compared with the groups not receiving cyclosporine treatment (group 3 vs group 4 and group 5 vs group $6, P<.01$ ). TSignificant difference compared with xenogeneic transplantation groups (group 3 vs group 5 and group 4 vs group $6, P<.05)$.

reached $51.6 \pm 3.98$ (control, $6.8 \pm 0.87)$ on day 4 and then peaked on day 7 ( $54.2 \pm 4.3$; control, $7.8 \pm 1.66)$. After day 7 , the number of macrophages started to decrease and largely decreased to a low level on day $28(17 \pm 1.95$; control 1, $8.8 \pm 1.16$ ). In groups 4, 5, and 6 the macrophage numbers on days $1,4,7$, and 28 were significantly decreased compared with those in group $3(P<.05)$. On day 28 , the macrophage numbers in groups 5 and 6 were as low as those in the control groups $(P>.10)$.

$\mathrm{CD}^{+}$cell infiltration is shown in Figure $1, C$ and $D$. In group 3 the number of $\mathrm{CD}^{+}$cells infiltrating was $7 \pm 0.63$ (control, $3.4 \pm 0.51$ ) on day $1,22 \pm 2.10$ (control, $2.8 \pm$ 0.66 ) on day 4 , and $40.8 \pm 2.87$ (control, $3.4 \pm 0.51$ ) on day 7. There were no significant differences between the number of $\mathrm{CD}^{+}$cells in group $3(4.8 \pm 0.58)$ and in control group $1(3.4 \pm 0.75)$ on day 28 . In groups 4,5 , and 6 the $\mathrm{CD} 8^{+}$cell numbers on days 4 and 7 were largely decreased compared with those in group 3. On the other hand, $\mathrm{CD} 4^{+}$cells infiltrated from day 4 (Figure 1, $E$ and $F$ ). In group 3 the numbers were $20.4 \pm 2.14$ (control, $3 \pm$ 0.84 ) and $30.4 \pm 0.72$ (control, $3 \pm 0.71$ ) on days 4 and 7 , respectively. In groups 4,5 , and $6 \mathrm{CD}^{+}$cell numbers on days 4 and 7 were largely decreased compared with those seen in group $3(P<.05)$. CD4 ${ }^{+}$cell numbers on day 28 in the cell-transplanted groups were as low as those in the control group.

\section{Time Course of Xeno- and Allo-SkM Survival}

Table 1 shows the quantification of SkMs at different time points after cell engraftment. There was no significant difference in the actual quantity of sry copies at 10 minutes among groups $\left(1-1.2 \times 10^{6} \mathrm{SkMs}\right.$ were left), and the average SkM number at 10 minutes after cell transplantation was used as baseline. In the SkM transplantation groups (groups 3-6) a remarkably rapid and massive loss of male DNA was observed after injection of male SkMs. A total of $94.6 \%, 90.7 \%, 91.2 \%$, and $88.9 \%$ of the SkMs were lost in groups $3,4,5$, and 6 , respectively, during the first 24 hours. These observations are consistent with earlier findings reported by other groups. ${ }^{1,12}$ Subsequently, the number of
SkMs showed a gradual increase until 4 weeks, which was probably a result of proliferation of surviving SkMs.

We also have shown the role of host immune response in donor SkM survival. In xeno-SkM-transplanted group 3, 5.37\% and $23.63 \%$ of SkMs were left on days 1 and 28, respectively. Both cyclosporine-treated xeno-SkM-transplanted group 4 and allo-SkM-transplanted group 5 showed a significant increase in total number of SkMs $(P<.01$, Table 1$)$. Furthermore, in group 6 allogeneic SkMs with cyclosporine treatment showed a superior survival in the host myocardium compared with the other cell-grafted groups $(P<.05)$.

\section{Heart Function Assessment}

Figure 2 shows heart function improvement by means of echocardiography with SkM transplantation. There was no significant difference in baseline heart performance (EF and FS) among the different groups. The EF and FS baselines in groups 1 through 6 were $43.50 \% \pm 2.6 \%$ and $24.80 \% \pm 1.7 \%$, $43.75 \% \pm 3.8 \%$ and $23.50 \% \pm 1.2 \%, 43.00 \% \pm 1.8 \%$ and $24.50 \% \pm 1.3 \%, 43.30 \% \pm 2.9 \%$ and $25 \% \pm 1.6 \%, 43.4 \% \pm$ $2.73 \%$ and $25.3 \% \pm 1 \%$, and $44.3 \% \pm 3.0 \%$ and $25.5 \% \pm$ $2.65 \%$, respectively. Four weeks after SkM transplantation, the EF and FS values in groups 1 through 6 were $44 \% \pm$ $1.4 \%$ and $25.5 \% \pm 1 \%, 44.13 \% \pm 3.4 \%$ and $26.25 \% \pm$ $0.75 \%, 49 \% \pm 1.5 \%$ and $28.8 \% \pm 2.2 \%, 52.5 \% \pm 1.2 \%$ and $31 \% \pm 0.8 \%, 50.33 \% \pm 2.07 \%$ and $31 \% \pm 2.12 \%$, and $54.2 \% \pm 1.57 \%$ and $31.25 \% \pm 2.22 \%$, respectively. Significant improvement of EF and FS were observed compared with baseline values (within-group comparison) in groups 3 through $6(P<.01)$, whereas no functional improvement in the DMEM-treated groups was observed (groups 1 and 2). When compared with those of groups 1 and 2, there was significant improvement of EF and FS values in all SkM transplantation groups (groups 3 and 5 [no cyclosporine treatment] vs group 1 and groups 4 and 6 [cyclosporine treatment] vs group $2, P<.01$ ). In groups 4 and 6, receiving both SkMs and cyclosporine, EF improved significantly compared with that seen in the groups not receiving cyclosporine treatment (group 4 vs group 3 and group 6 vs group $5, P<.05)$. However, even though SkMs 

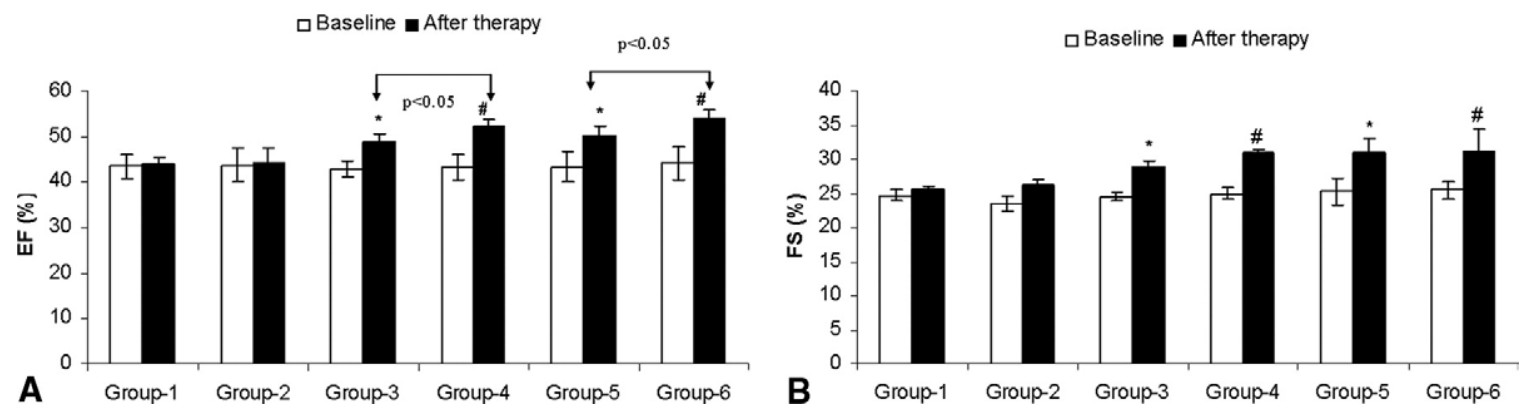

Figure 2. Echocardiographic analysis showed improved heart function after skeletal myoblast transplantation. There was no significant difference in baseline heart performance (ejection fraction [EF] and fractional shortening [FS] among the different groups of animals. Within groups, significant improvement in EF and FS was observed after skeletal myoblast transplantation (groups 3-6) compared with baseline values $(P<.01)$, whereas there was no functional improvement in the DMEM-treated groups (groups 1 and 2). Between-group analyses: *Significant improvement of EF/FS compared with that seen in control group 1 (comparison among groups not receiving cyclosporine treatment). TSignificant improvement of EF/FS compared with control group 2 (comparison among cyclosporine-treated groups, $P<.01)$. In the EF arm (A), with cyclosporine treatment, EF increased to a significant level compared with that seen in the groups not receiving cyclosporine treatment (group 4 vs group 3 and group 6 vs group $5, P<.05)$. No significant improvement was observed in allogeneic groups compared with that of xenogeneic groups (group 5 vs group 3 and group 6 vs group 4). In the FS arm (B) no significant difference was observed in the skeletal myoblast transplantation groups (groups 3-6) after cell therapy.

survived better in the allogeneic transplantation groups (34\% of SkMs in group 5 and $68 \%$ of SkMs in group 6) compared with the xenogeneic groups (24\% in group 3 and $55 \%$ in group 4), EF did not show any significant difference (group 5 vs group 3 and group 6 vs group $4, P>.1$ ). This might be a result of the fact that the extent of cell survival increase (from $24 \%$ to $34 \%$ and from $55 \%$ to $68 \%$ ) was not as large as that in groups treated with cyclosporine (from $24 \%$ to $55 \%$ and from $34 \%$ to $68 \%$ ). Actually, a previous study has demonstrated a dose-response effect of SkMs on improvement of heart function. ${ }^{13}$ However, if the increase of cell survival is not big enough, it might not result in significant improvement in heart function.

\section{Discussion}

Allomyoblasts and xenomyoblasts provide alternative sources for myoblast-based cardiac cell therapy. However, the issue of host immune responses hampers their clinical application. This study was mainly carried out to investigate host immune cell kinetics, survival profile of the donor SkMs, and SkM graft efficacy after xenogeneic and allogeneic transplantation into infarcted myocardium. We observed the SkM survival dynamics in an infarcted heart and demonstrated that the immunocytes, including $\mathrm{CD}^{+}$cells, $\mathrm{CD} 8^{+}$cells, and macrophages, severely infiltrated during the acute stage after myoblast transplantation and then subsided. Furthermore, cyclosporine treatment inhibited the early infiltration of immunocytes, promoted myoblast survival, and improved heart function. These findings suggest the feasibility of SkM transplantation from nonautologous sources, especially allomyoblasts.

Most previous studies have used hSkMs for autologous transplantation, ${ }^{7,8}$ which has left the in vivo behavior of hSkMs poorly studied. In 2003, Pagani and colleagues ${ }^{9}$ were the first to show direct evidence for hSkM survival and differentiation into mature myofibers in myocardium. Later, Hagege and associates ${ }^{10}$ also demonstrated the viability and differentiation of hSkM grafts. However, to further investigate the fundamental cellular behavior of hSkMs, in particular their surviving efficiency after transplantation into a cardiac environment, a small-animal model in which whole graft cells could be easily collected and quantified after animal death would be ideal. In our study a rat heart infarction model was used.

Our study has shown the early dynamics of SkMs, which enables us to have a better understanding of the early cellular behavior of SkMs in vivo, especially hSkMs. In our study, at 10 minutes after SkM transplantation, only 1 to $1.2 \times 10^{6} \mathrm{SkMs}$ were left, and then majority of the remaining SkM signals were rapidly lost by day 1 after cell transplantation. Previous studies have described this rapid myoblast loss after implantation into skeletal muscles and normal heart tissue $e^{1,12,14,15}$ and have attributed this massive cell loss to mechanical loss, including mechanical leakage and washout, ${ }^{16,17}$ cell redistribution to other organs, ${ }^{18}$ and cell death. ${ }^{1,12,14,15}$ The present study used a myocardial infarction model, which is more similar to the clinical settings. Furthermore, there was no significant difference in 
actual quantity of sry copies at 10 minutes among groups, which might exclude the effects of immunoresponses on cell loss in the first 10 minutes. After 10 minutes, cell survival rates changed among various SkM transplantation groups, which suggested an immune rejection effect during this phase. After day 1, a gradual increase in the number of myoblasts was observed until 4 weeks after cell transplantation, resulting from the SkM proliferation outbalancing the gradual loss. Previous studies have shown that SkM proliferation is stimulated by several growth factors, such as fibroblast growth factor 2, epidermal growth factor, insulinlike growth factor 1 , and stem cell factor. ${ }^{19}$ Because SkM proliferation stops on differentiation, the proliferation might be enhanced by TGF- $\beta$, which represses myoblast differentiation. ${ }^{20}$ In addition, some isoforms of platelet-derived growth factor also regulate myoblast proliferation and differentiation. ${ }^{21}$ To our knowledge, the mechanism that regulates SkM proliferation remains unclear after transplantation into the myocardium, which might be an interesting field for future investigation. Of greater significance, our study showed that the grafted hSkMs and rSkMs survived and differentiated well in the immunocompetent hosts, even without any immunosuppression. Previous animal studies have accumulated some evidence of xenomyoblast ${ }^{22}$ and allomyoblast ${ }^{23,24}$ transplantation into myocardium. Using the minimal dosage of cyclosporine $\left(5 \mathrm{mg} \cdot \mathrm{kg}^{-1} \cdot \mathrm{d}^{-1}\right)^{22}$ or without immunosuppressive treatment, ${ }^{23,24}$ they have demonstrated SkM acceptance. More recently, our group reported a 7-month survival of xenomyoblasts by using a minimal dose of cyclosporine $\left(5 \mathrm{mg} \cdot \mathrm{kg}^{-1} \cdot \mathrm{d}^{-1}\right)$ for 6 weeks after transplantation into the infarcted hearts. ${ }^{5}$ In light of these data and our present study, we suggest that SkMs enjoy a nonautologous graft acceptance in the myocardium, a finding that might have far-reaching implications in clinical perspective. The nonautologous graft acceptance might result from the relatively privileged transplantation site of the myocardium, where presentation and recognition of human leukocyte antigen might not take place because of the lack of a lymphatic drainage system, ${ }^{25}$ and the nature of the cells with less expression of human leukocyte antigen, which might be due to the differentiation of SkMs, establishment of chimerism, or both. ${ }^{2,6}$ On the other hand, other authors showed that allogeneic myoblasts were highly immunogenic. ${ }^{14,26}$ However, they transplanted myoblasts into muscle tissue, not heart tissue, which might explain the discrepancy.

Another important finding of our study is the negative correlation between the number of immunocytes and the total number of SkMs. Allomyoblasts and xenomyoblasts are typically rejected by the host immune system in response to inherent histoincompatibility. Even autologous myoblasts can induce immune responses toward antigenic molecules expressed after exposure to tissue culture condi- tions or transfer of genes. ${ }^{27}$ The host immune response has been a confounding factor in the better understanding of SkM survival after transplantation. Surprisingly, we found that immunocytes infiltrated severely only within the first week after myoblast transplantation into the infarcted heart. Importantly, the number of infiltrating immunocytes was largely decreased to a low level after 4 weeks, which might be attributed to the allomyoblast or xenomyoblast differentiation. Our study demonstrated a significant role of immune cells in the early death of donor SkMs, which is supported by close correlation between the number of immunocytes and the total number of SkMs shown in our study. In cyclosporine-treated groups or in allogeneic transplantation groups, SkMs survived better in the more immunocompatible condition (less immunocytes infiltrated) compared with xenogeneic transplantation.

From our study, administration of cyclosporine (10 $\mathrm{mg} \cdot \mathrm{kg}^{-1} \cdot \mathrm{d}^{-1}$ starting 5 days before cell transplantation and continuing to animal death) restrained the infiltration of the immunocytes, therefore enhancing SkM survival and improving heart performance. This has significant implications, especially in clinical cases. The dosage and initiation time of cyclosporine administration in the present study were very similar to those reported in the first case report of allomyoblast transplantation for coronary artery disease, which showed that administration of cyclosporine (5-7 $\mathrm{mg} \cdot \mathrm{kg}^{-1} \cdot \mathrm{d}^{-1}$ beginning 5 days before cell transplantation and lasting for 8 weeks) was effective and led to 9-month retention of hSkMs. ${ }^{28}$ It is recommended to initiate the cyclosporine treatment several days before cell therapy to achieve a stable blood concentration of cyclosporine and sufficient immunosuppression before cell transplantation procedures, because the immunocytes infiltrate severely in the acute phase after SkM transplantation. In our study, on day 28 , the immunocytes subsided compared with levels at earlier time points. This suggests early cessation of cyclosporine treatment (off cyclosporine at 8 weeks after grafting, as performed in the clinical case report) in nonautologous SkM transplantation. However, the effects need to be further monitored both in animal studies and clinical cases.

In conclusion, allomyoblasts survive better than do xenomyoblasts after transplantation into infarcted myocardium. After inhibition of immunocyte infiltration by immunosuppressive treatment, the SkM survival is enhanced, with improved heart performance. This suggests that nonautologous SkM transplantation is feasible with immunosuppressive treatment, especially for allomyoblasts.

\section{References}

1. Suzuki K, Murtuza B, Beauchamp JR, Smolenski RT, Varela-Carver A, Fukushima S, et al. Dynamics and mediators of acute graft attrition after myoblast transplantation to the heart. FASEB J. 2004;18:1153-5.

2. Hans R, Elina M, Veronica P, Murry CE. Evidence for fusion between cardiac and skeletal muscle cells. Circ Res. 2004;94:e56-60. 
3. Leobon B, Garcin I, Menasche P, Vilquin JT, Audinat E, Charpak S. Myoblasts transplanted into rat infarcted myocardium are functionally isolated from their host. Proc Natl Acad Sci U S A. 2003;100:7808-11.

4. Pouzet B, Vilquin JT, Hagege AA, Scorsin M, Messas E, Fiszman M, et al. Factors affecting functional outcome after autologous skeletal myoblast transplantation. Ann Thorac Surg. 2001;71:844-50.

5. Haider HK, Jiang SJ, Ye L, Aziz S, Law PK, Sim EKW. Effectiveness of transient immunosuppression using cyclosporine for xenomyoblast transplantation for cardiac repair. Transplant Proc. 2004;36:232-5.

6. Ye L, Haider HKh, Jiang S. Fusion between myoblasts and pig cardiomyocytes is the mechanism of survival of xenotransplanted human skeletal myoblasts in pig heart [abstract]. Eur Heart J. 2005; 26(suppl):320.

7. Menasche P, Hagege AA, Scorsin M, Pouzet B, Desnos M, Duboc D, et al. Myoblast transplantation for heart failure. Lancet. 2001;357: 279-80.

8. Smits PC, van Geuns RJ, Poldermans D, Bountioukos M, Onderwater EE, Lee $\mathrm{CH}$, et al. Catheter-based intramyocardial injection of autologous skeletal myoblasts as a primary treatment of ischemic heart failure: clinical experience with six-month follow-up. J Am Coll Cardiol. 2003;42:2063-9.

9. Pagani FD, DerSimonian H, Zawadzka A, Wetzel K, Edge AS, Jacoby $\mathrm{DB}$, et al. Autologous skeletal myoblasts transplanted to ischemiadamaged myocardium in humans. Histological analysis of cell survival and differentiation. J Am Coll Cardiol. 2003;41:879-88.

10. Hagege AA, Carrion C, Menasche P, Vilquin JT, Duboc D, Marolleau JP, et al. Viability and differentiation of autologous skeletal myoblast grafts in ischaemic cardiomyopathy. Lancet. 2003;361:491-2.

11. Niagara MI, Haider HKh, Ye L, Koh VS, Lim YT, Poh KK, et al. Autologous skeletal myoblasts transduced with a new adenoviral bicistronic vector for treatment of hind limb ischemia. J Vasc Surg. 2004;40:774-85.

12. Beauchamp JR, Pagel CN, Partridge TA. A dual-marker system for quantitative studies of myoblast transplantation in the mouse. Transplantation. 1997;63:1794-7.

13. Pouzet B, Vilquin JT, Hagege AA, Scorsin M, Messas E, Fiszman M. Factors affecting functional outcome after autologous skeletal myoblast transplantation. Ann Thorac Surg. 2001;71:844-50.

14. Skuk D, Caron N, Goulet M, Roy B, Espinosa F, Tremblay JP. Dynamics of the early immune cellular reactions after myogenic cell transplantation. Cell Transplant. 2002;11:671-81.

15. Hodgetts SI, Beilharz MW, Scalzo AA, Grounds MD. Why do cultured transplanted myoblasts die in vivo? DNA quantification shows enhanced survival of donor male myoblasts in host mice depleted of
CD4+ and CD8+ cells or Nk1.1+ cells. Cell Transplant. 2000; 9:489-502.

16. Ishida M, Tomita S, Nakatani T, Kagawa K, Yamaguchi T, Suga M, et al. Acute effects of direct cell implantation into the heart: a pressurevolume study to analyze cardiac function. J Heart Lung Transplant. 2004;23:881-8.

17. Teng CJ, Luo J, Chiu RC, Shum-Tim D. Massive mechanical loss of microspheres with direct intramyocardial injection in the beating heart: implications for cellular cardiomyoplasty. J Thorac Cardiovasc Surg. 2006;132:628-32.

18. Aicher A, Brenner W, Zuhayra M, Badorff C, Massoudi S, Assmus B et al. Assessment of the tissue distribution of transplanted human endothelial progenitor cells by radioactive labeling. Circulation. 2003; 107:2134-9.

19. Deasy BM, Qu-Peterson Z, Greenberger JS, Huard J. Mechanisms of muscle stem cell expansion with cytokines. Stem Cells. 2002;20:50-60.

20. Vaidya TB, Rhodes SJ, Taparowsky EJ, Konieczny SF. Fibroblast growth factor and transforming growth factor $\beta$ repress transcription of the myogenic regulatory gene MyoD1. Mol Cell Biol. 1989;9:3576-9.

21. Yablonka-Reuveni Z, Balestreri TM, Bowen-Pope DF. Regulation of proliferation and differentiation of myoblasts derived from adult mouse skeletal muscle by specific isoforms of PDGF. J Cell Biol. 1990;111:1623-9

22. Reinecke H, Murry CE. Transmural replacement of myocardium after skeletal myoblast grafting into the heart. Too much of a good thing? Cardiovasc Pathol. 2000;9:337-44.

23. Suzuki K, Brand NJ, Smolenski RT, Jayakumar J, Murtuza B, Yacoub $\mathrm{MH}$. Development of a novel method for cell transplantation through the coronary artery. Circulation. 2000;102(suppl):III359-64.

24. Suzuki K, Smolenski RT, Jayakumar J, Murtuza B, Brand NJ, Yacoub MH. Heat shock treatment enhances graft cell survival in skeletal myoblast transplantation to the heart. Circulation. 2000;102(suppl): III216-21.

25. Morris PJ. The immunobiology of cell transplantation. Transplant Proc. 1992;24:2865.

26. Camirand G, Caron NJ, Turgeon NA, Rossini AA, Tremblay JP. Treatment with anti-CD154 antibody and donor-specific transfusion prevents acute rejection of myoblast transplantation. Transplantation. 2002;73:453-61.

27. Smythe GM, Grounds MD. Exposure to tissue culture conditions can adversely affect myoblast behavior in vivo in whole muscle grafts: implications for myoblast transfer therapy. Cell Transplant. 2000;9: 379-93.

28. Law PK, Law DM, Lu P, Sim EKW, Haider KH, Ye L, et al. Human myoblast genome therapy. J Geriatr Cardio. 2006;3:135-51. 

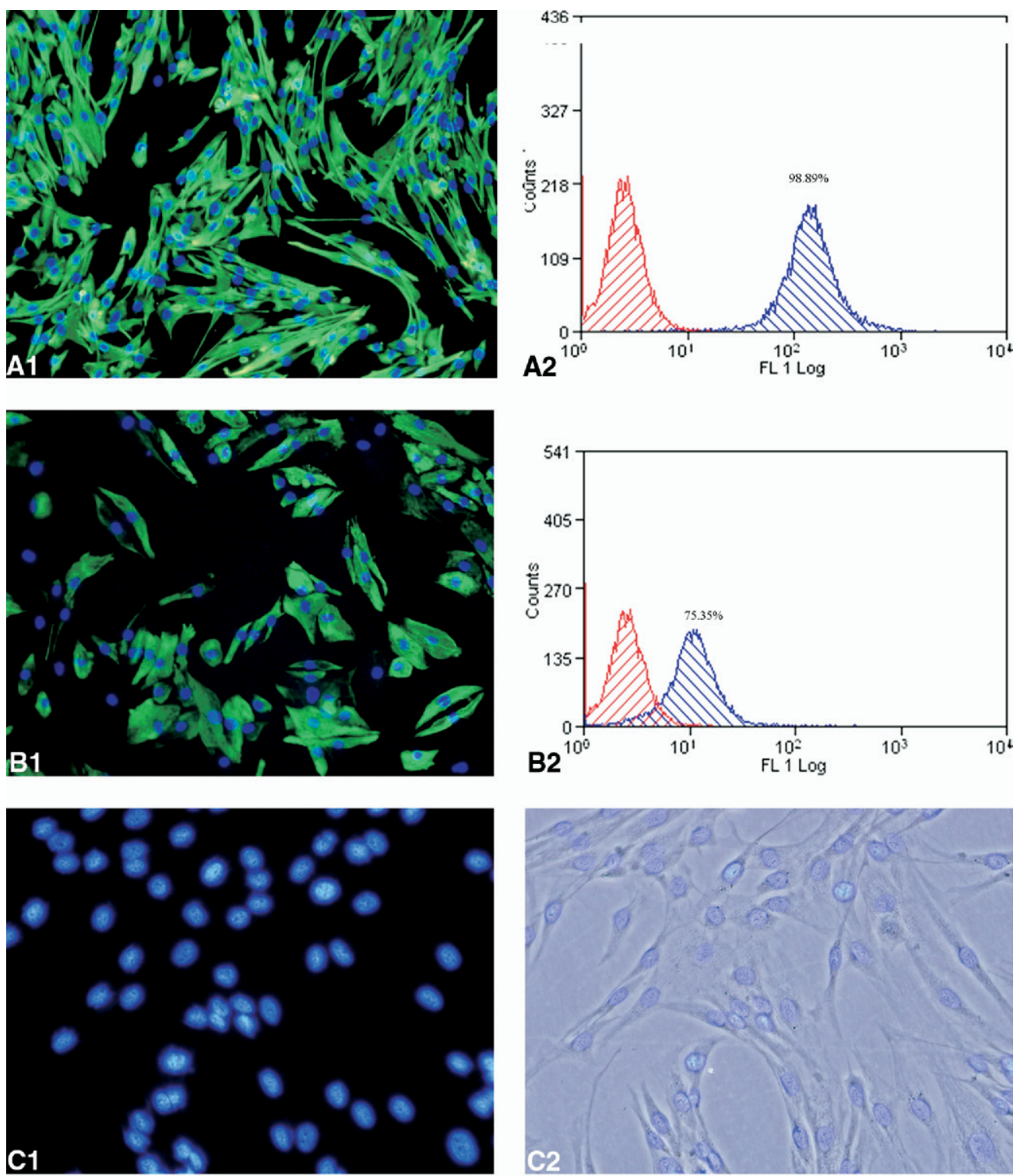

Figure E1. Immunostaining and flow cytometric assay of skeletal myoblasts for desmin and $4^{\prime}, 6^{\prime}$-diamidino-2-phenylindole hydrochloride and lac-z labeling efficiency. A1, Green fluorescent cytoplasm showing desmin-positive skeletal myoblasts. A2, Human skeletal myoblasts were $98.89 \%$ pure (blue curve) for desmin expression when gated for control at $1.02 \%$ (red curve) by means of flow cytometric assay. B1, Desminpositive rat skeletal myoblasts. B2, Rat skeletal myoblasts were $75.35 \%$ pure (blue) for desmin expression when gated for control at $1.02 \%$ (red) by means of flow cytometric assay. C1 4',6'-Diamidino-2-phenylindole hydrochloride-labeled skeletal myoblasts (blue nuclei). C2, Merged image of panel $\mathrm{C1}$ and phase-contrast image to show total number of cells. D, Lac-zpositive cells with green nuclei. (Original magnification: $200 \times$ ). 

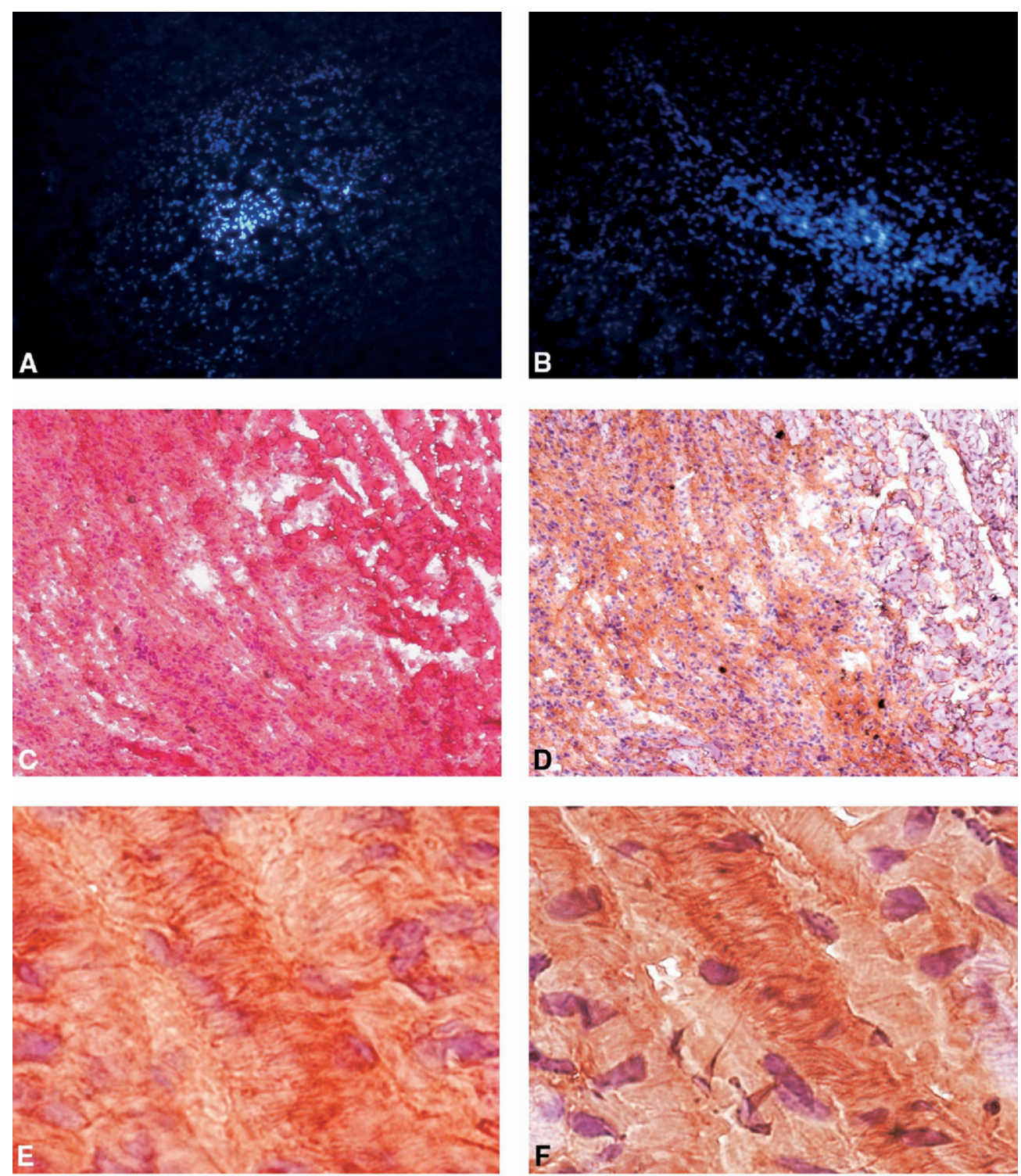

Figure E2. Myoblast survival and differentiation after transplantation. A, 4' ,6' -Diamidino2-phenylindole hydrochloridelabeled skeletal myoblasts 7 days after transplantation. Note the presence of cells at the injection site without orientation. B, 4' , 6' -Diamidino2-phenylindole hydrochloridelabeled skeletal myoblasts 28 days after transplantation showed typically aligned orientation, which followed host muscle architecture. C, Hematoxylin and eosin staining to show the myocardium of continuous section from panel $B$. D, Myosin heavy chain (slow isoform) immunostaining counterstained with hematoxylin to show myoblast differentiation and (E). F, Myosin heavy chain (fast isoform) immunostaining counterstained with hematoxylin. G, Myoblast survival confirmed by lac-z staining (green nuclei) counterstained with hematoxylin. (Original magnifications: A-D, $100 \times$; E-F, $800 \times$; G, 400×).

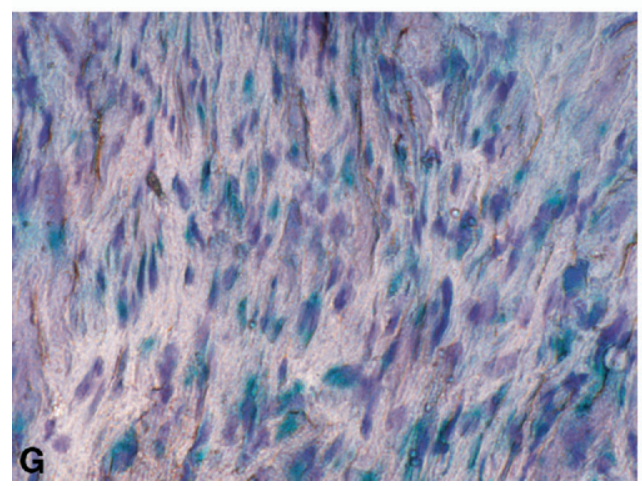

